\title{
Does ethnicity contribute to the control of cardiovascular risk factors among patients with type 2 diabetes?
}

\begin{abstract}
This study aimed to examine the control of cardiovascular risk factors among the ethnic groups with type 2 diabetes in Malaysia. The authors analyzed the data of 70092 adults from the Malaysian diabetes registry database. Malays had the worst achievement of target for most of the risk factors. Indians had poor achievement of control for waist circumference (odds ratio $[\mathrm{OR}]=0.6,95 \%$ confidence interval $[\mathrm{CI}]=0.6-0.7$ ) and high-density lipoprotein cholesterol $(\mathrm{OR}=0.5,95 \% \mathrm{CI}=0.4-0.5)$. As compared with the Malays, the Chinese had a better achievement of target control for the risk factors, including the following: body mass index $(\mathrm{OR}=1.3,95 \% \mathrm{CI}=1.2-1.4)$, blood pressure $(\mathrm{OR}=1.3,95 \% \mathrm{CI}=1.3-1.4)$, total cholesterol $(\mathrm{OR}=1.7,95 \% \mathrm{CI}=1.6-1.8)$, low-density lipoprotein cholesterol $(\mathrm{OR}=1.7,95 \%$ $\mathrm{CI}=1.6-1.8)$, glycated hemoglobin $\mathrm{A} 1 \mathrm{c}(\mathrm{OR}=1.4,95 \% \mathrm{CI}=1.3-1.4)$ and fasting blood glucose $(\mathrm{OR}=1.4,95 \% \mathrm{CI}=1.3-1.5)$. Ethnicity, sociocultural factors, and psychobehavioral factors should be addressed in designing and management strategies for the control of cardiovascular risk factors among type 2 diabetes patients.
\end{abstract}

Keyword: Cardiovasular risk factors; Type 2 diabetes; Ethnic difference; Malaysia 